\title{
Live-virus exposure of vaccine-protected macaques alters the anti-HIV-1 antibody repertoire in the absence of viremia
}

\author{
Barbara C Bachler ${ }^{1,2}$, Michael Humbert ${ }^{1,3}$, Samir K Lakhashe ${ }^{1,3}$, Robert A Rasmussen ${ }^{1,3}$ and Ruth M Ruprecht ${ }^{1,3^{*}}$
}

\begin{abstract}
Background: We addressed the question whether live-virus challenges could alter vaccine-induced antibody (Ab) responses in vaccinated rhesus macaques (RMs) that completely resisted repeated exposures to R5-tropic simian-human immunodeficiency viruses encoding heterologous HIV clade C envelopes (SHIV-Cs).

Results: We examined the Ab responses in aviremic RMs that had been immunized with a multi-component protein vaccine (multimeric HIV-1 gp160, HIV-1 Tat and SIV Gag-Pol particles) and compared anti-Env plasma Ab titers before and after repeated live-virus exposures. Although no viremia was ever detected in these animals, they showed significant increases in anti-gp140 Ab titers after they had encountered live SHIVs. When we investigated the dynamics of anti-Env Ab titers during the immunization and challenge phases further, we detected the expected, vaccine-induced increases of Ab responses about two weeks after the last protein immunization. Remarkably, these titers kept rising during the repeated virus challenges, although no viremia resulted. In contrast, in vaccinated RMs that were not exposed to virus, anti-gp140 Ab titers declined after the peak seen two weeks after the last immunization. These data suggest boosting of pre-existing, vaccine-induced Ab responses as a consequence of repeated live-virus exposures. Next, we screened polyclonal plasma samples from two of the completely protected vaccinees by peptide phage display and designed a strategy that selects for recombinant phages recognized only by Abs present after - but not before - any SHIV challenge. With this "subtractive biopanning" approach, we isolated V3 mimotopes that were only recognized after the animals had been exposed to live virus. By detailed epitope mapping of such anti-V3 Ab responses, we showed that the challenges not only boosted pre-existing binding and neutralizing Ab titers, but also induced Abs targeting neo-antigens presented by the heterologous challenge virus.
\end{abstract}

Conclusions: Anti-Env Ab responses induced by recombinant protein vaccination were altered by the multiple, live SHIV challenges in vaccinees that had no detectable viral loads. These data may have implications for the interpretation of "vaccine only" responses in clinical vaccine trials.

Keywords: Macaque model, Recombinant protein vaccine, Heterologous R5 SHIV clade C challenge, Complete protection, Subtractive peptide phage display, V3 crown, Boosting of vaccine-induced Ab titers after multiple challenges, Neo-antigen reactivity

\footnotetext{
* Correspondence: ruth_ruprecht@dfci.harvard.edu

'Department of Cancer Immunology and AIDS, Dana-Farber Cancer Institute, Boston, MA 02215, USA

${ }^{3}$ Harvard Medical School, Boston, MA 02215, USA

Full list of author information is available at the end of the article
} 


\section{Background}

According to UNAIDS/WHO, more than 2 million people are newly infected with HIV-1 each year [1]. The design of an effective vaccine is important to control the global expansion of the AIDS pandemic [2]. In the context of vaccine efficacy in humans, only the RV144 trial showed promising results so far [3] and recent follow-up studies identified vaccine-induced correlates of protection [4,5]. Additionally, biologically relevant non-human primate (NHP) models are used in HIV-1/AIDS research to gain information about vaccine-induced immunity [6,7]. In contrast to clinical studies in humans, NHPs can be deliberately challenged with well characterized virus inocula. This allows a subsequent detailed analysis of virus-specific consequences on pre-existing (vaccineinduced) immune responses.

Previously, we described different immunization/challenge studies in rhesus macaques (RMs) that were vaccinated with recombinant protein immunogens (multimeric HIV-1 clade C (HIV-C) gp160, HIV-1 Tat and SIV Gag-Pol particles). Upon repeated challenge with the heterologous R5-tropic simian-human immunodeficiency viruses encoding HIV-1 clade C envelopes (SHIV-Cs), all controls became infected and developed high peak viremia, whereas some vaccinees remained aviremic throughout ([8-12] and unpublished). Here, we focused on the antibody $(\mathrm{Ab})$ responses in vaccinees that had resisted all mucosal challenges completely and asked two questions: i) is there a quantitative difference in the anti-Env $\mathrm{Ab}$ titers after versus before live-virus exposures in animals without detectable viremia? And ii) is there a qualitative difference in the $\mathrm{Ab}$ responses after versus before live-virus exposures in the same animals due to newly induced Abs targeting neo-antigens that were presented by the heterologous challenge virus? To address these issues, we decided to dissect the Ab responses in completely protected RMs further and to take an imprint of the $\mathrm{Ab}$ paratopes after virus challenges using recombinant phage libraries encoding random peptides.

\section{Results}

\section{Dynamics of anti-Env Ab responses in vaccinated RMs}

To test whether live-virus exposures could induce quantitative changes in the vaccine-induced $\mathrm{Ab}$ responses in RMs where the virus failed to cause any detectable viremia, we first investigated Env-specific plasma Ab titers at time points before and after virus challenge. We examined plasma samples of two vaccine-protected RMs, RRi-11 and RTr-11, that had been enrolled in the same vaccine/challenge study [12] and challenged multiple times with the R5 clade C SHIV-1157ipEL-p [13] (Group 1 in Figure 1A, B and Table 1). Monkey RRi-11 fulfilled all criteria for sterilizing immunity, whereas RTr-11 showed anamnestic cellular immune responses compatible with cryptic infection ([12] and Table 1). As a control, we also investigated anti-Env binding Ab titers in eight animals that had been part of an unpublished immunogenicity study (Group 2, Figure 1C, D). Importantly, these animals were immunized similarly as the monkeys from Group 1, including the same adjuvant (incomplete Freund's adjuvant, IFA). To allow a direct comparison of both groups, we adjusted the time points for Group 2 and designated the time of last protein immunization as week -2 . For both groups, we tested plasma collected at weeks -1 and 0 and up to 8 weeks post last protein immunization (weeks 1, 2 and 6). Most animals showed an increase of anti-gp140 Ab titers between week -1 (light red) and week 0 (dark red) (Figure 1B, D), which reflects the expected boosting of $\mathrm{Ab}$ responses during the two weeks after the last protein immunization (week -2). Yet, when we examined the anti-gp140 binding $\mathrm{Ab}$ responses at later time points, only the two vaccinees exposed to live virus showed a continuing increase of anti-gp140 Ab titers (Group 1, blue bars, Figure 1B). In contrast, the Ab levels in Group 2 controls peaked at the two weeks post last immunization and declined during the time window that corresponds to the virus challenge in Group 1 (green bars, Figure 1D). Taken together, we conclude that the third protein immunization led to a boosting of anti-gp140 $\mathrm{Ab}$ responses, which reached a peak within two weeks (week 0). Importantly, these Env-specific Ab titers continued to increase only in the RMs exposed repeatedly to live virus, although no viremia was ever detected. These data suggest a boosting of anti-Env Abs by virus challenges that did not result in systemic infection.

Next, we extended our analysis and examined the antiEnv Ab binding titers in three additional vaccinees that were also completely protected but had been enrolled in different vaccine/challenge studies ([8-11] and unpublished). The immunogens and challenge viruses used are listed in Table 1. Although the multigenic immunogen composition had varied among the studies, all of the vaccinees had received the same multimeric HIV-C gp160. When we compared the vaccine-induced antigp140 Ab titers (Methods) with the Ab responses against the same protein but measured after virus exposures, we observed a statistically significant increase of anti-Env specific Abs not only for the two RMs mentioned, RRi11 and $\operatorname{RTr}-11(P<0.0001$ and $P=0.002$, respectively $)$, but also for RM RAt-9 $(P=0.03)$, which had been challenged with a different virus (Figure 1E). Also, the protected RM ROb-12, which had resisted five low-dose challenges with the tier 2 SHIV-2873Nip (unpublished data), showed a trend towards higher Env-specific plasma Ab titers after the live-virus encounters $(P=0.08)$. In the fifth aviremic vaccinee, RQe-10, the anti-Env binding Ab titers did not change. 


\section{A}

Group 1: vaccine/challenge study

C

Group 2: immunogenicity study

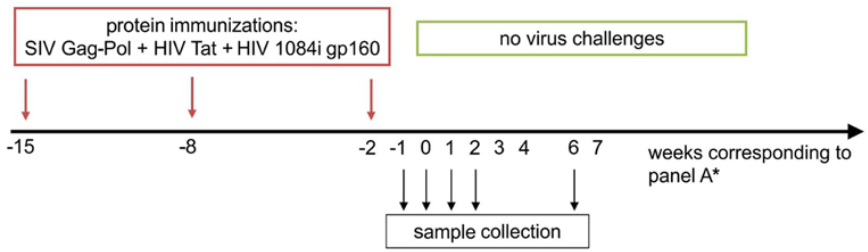

* last boost: designated as week -2

E

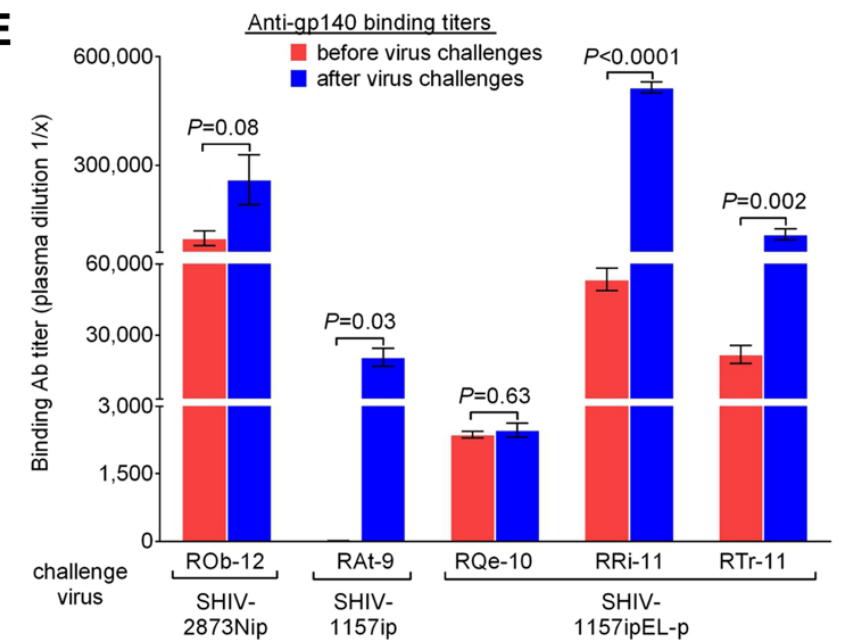

B

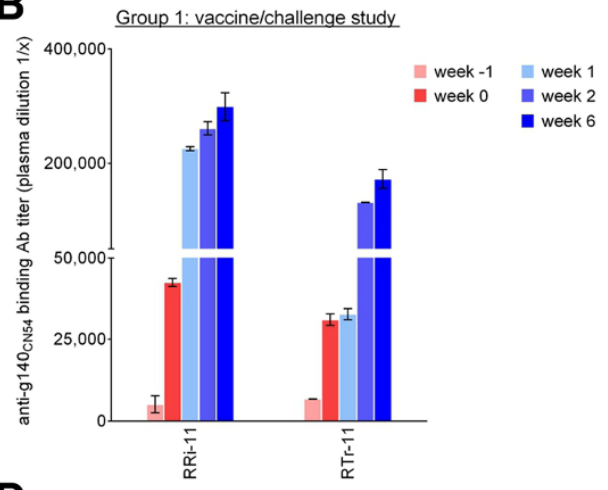

D
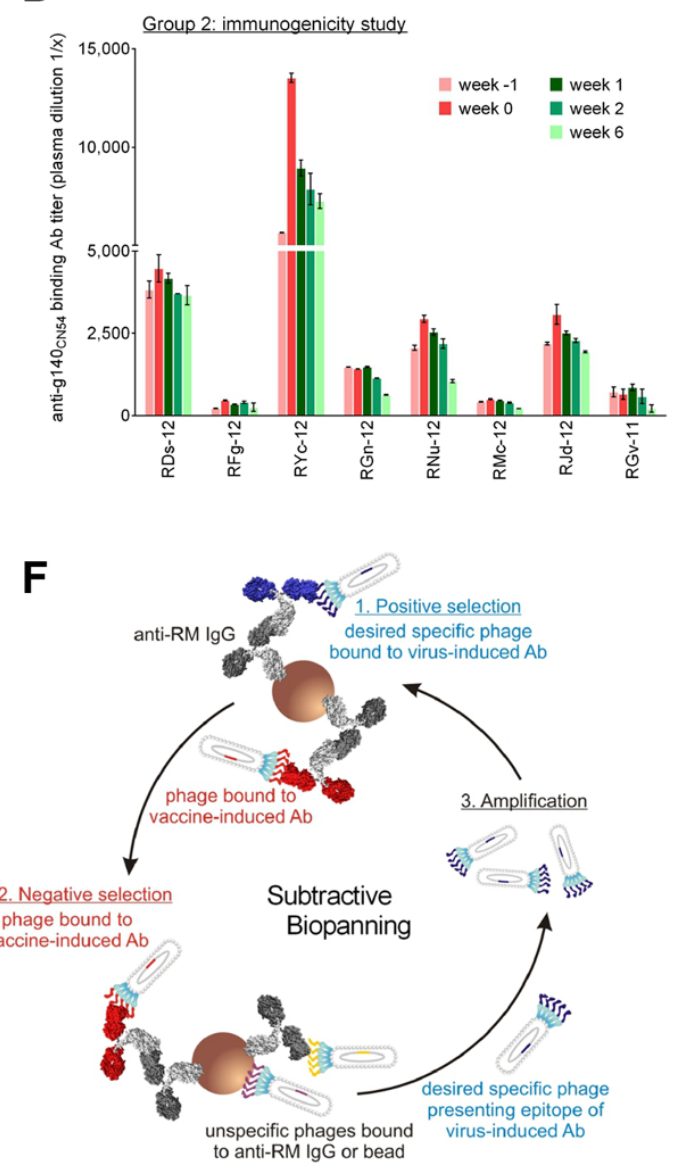

Figure 1 Anti-Env Ab responses in vaccinated RMs before and after virus challenge. A. Time line of vaccine/challenge study [12]. In red, immunization phase; in blue, challenge phase. Plasma samples were collected at weeks -1, 0, 1, 2 and 6. B. Quantitative ELISA to determine Envspecific Ab titers in two vaccine-protected RMs. In red, time points post $3^{\text {rd }}$ immunization and pre-challenge; in blue, time points post challenge. C. Time line of immunogenicity study (unpublished). The last protein immunization was designated as week -2 , so that the subsequent weeks would correspond to the study in (A). D. Quantitative ELISA to determine Env-specific Ab titers in eight vaccinated, but not challenged RMs. In red, 1 or 2 weeks post $3^{\text {rd }}$ immunization; in green, subsequent time points. E. The gp140 CN54-specific Ab titers were compared before and after live-virus challenges in five completely protected vaccinees. The challenge viruses used are indicated. Height of each bar, average titer from three independent assays; error bars, standard error of the mean (SEM). $P$ values are shown ( $P<0.05$ was considered significant). F. Subtractive biopanning. Three rounds of selection were performed to identify Ab epitopes linked to live-virus exposure. Each round of selection consists of (1) positive selection, (2) negative selection and (3) amplification of the selected phages. Light gray, the Fc portion of all Abs. Dark gray, Fab portion of anti-RM lgG immobilized onto paramagnetic beads via the Fc. Positive selection used week 7 plasma from a protected animal. In dark blue, Fab portions of the live-virus induced Abs and the corresponding phages. Positively selected recombinant phages were counter-selected with plasma from the same vaccinee but collected at week 0 (containing vaccine-induced Abs only). In red, Fab portions of negative selector Abs and the corresponding bound phages. Purple or yellow phages, unspecific phages bound to anti-RM Ab or beads, respectively. 
Table 1 Immune status of vaccinees after all live-virus challenges

\begin{tabular}{|c|c|c|c|c|c|c|}
\hline $\begin{array}{l}\text { Level of } \\
\text { protection }\end{array}$ & $\begin{array}{l}\text { Animal } \\
\text { name }\end{array}$ & $\begin{array}{l}\text { Virological } \\
\text { outcome }\end{array}$ & Interpretation & Immunogens & $\begin{array}{l}\text { Challenge viruses } \\
\text { (challenge route) }\end{array}$ & $\begin{array}{l}\text { Enrolled in } \\
\text { study }\end{array}$ \\
\hline \multirow[t]{5}{*}{ Complete } & ROb-12 & Aviremic & Cryptic infection & $\begin{array}{l}\text { HIV-C gp160 and gp145 } \\
\text { + SIV Gag overlapping } \\
\text { synthetic peptides (OSP) } \\
\text { + HIV Tat OSP } \\
\text { + SIV Nef OSP }\end{array}$ & $\begin{array}{l}\text { Multiple low-doses with } \\
\text { SHIV-2873Nip (intrarectal) [14] }\end{array}$ & unpublished \\
\hline & RAt-9 & Aviremic & Cryptic infection & $\begin{array}{l}\text { HIV-C gp160 } \\
+ \text { SIV Gag-Pol particles } \\
+ \text { HIV Tat }\end{array}$ & $\begin{array}{l}\text { Single low-dose with SHIV-1157ip } \\
\text { (oral) and single high-dose with } \\
\text { SHIV-1157ipd3N4 (intrarectal) [15] }\end{array}$ & [8-10] \\
\hline & RQe-10 & Aviremic & $\begin{array}{l}\text { Sterilizing } \\
\text { immunity }\end{array}$ & $\begin{array}{l}\text { Listeria monocytogenes } \\
\text { expressing SIV gag } \\
+ \text { Ad5hr encoding SIV gag } \\
+ \text { HIV-C gp160 } \\
+ \text { HIV Tat }\end{array}$ & $\begin{array}{l}\text { Multiple low-doses with } \\
\text { SHIV-1157ipEL-p (intrarectal) [13] }\end{array}$ & [11] \\
\hline & RRi-11 & Aviremic & $\begin{array}{l}\text { Sterilizing } \\
\text { immunity }\end{array}$ & $\begin{array}{l}\text { HIV-C gp160 } \\
+ \text { SIV Gag-Pol particles } \\
+ \text { HIV Tat }\end{array}$ & $\begin{array}{l}\text { Multiple low-doses and one high-dose } \\
\text { with SHIV-1157ipEL-p (intrarectal) [13] }\end{array}$ & [12] \\
\hline & RTr-11 & Aviremic & Cryptic infection & & & \\
\hline \multirow[t]{2}{*}{ Partial } & $\mathrm{RBr}-11$ & $\begin{array}{l}\text { Lower peak } \\
\text { viremia }\end{array}$ & $\begin{array}{l}\text { Chronic systemic } \\
\text { infection }\end{array}$ & & & \\
\hline & RGe-11 & $\begin{array}{l}\text { Aviremic during } \\
\text { low-dose } \\
\text { challenges }\end{array}$ & $\begin{array}{l}2 \text { low-level blips } \\
\left(<10^{4} \text { copies } / \mathrm{ml}\right)\end{array}$ & & & \\
\hline None & RDo-11 & No protection & $\begin{array}{l}\text { Chronic systemic } \\
\text { infection }\end{array}$ & & & \\
\hline
\end{tabular}

Of note, we have also recently examined anti-Tat Ab responses for animals RAt-9, RQe-10, RRi-11 and RTr-11 before and after live-virus exposures [16]. We observed a similar boosting of Ab levels in the same animals (again no changes for RQe-10). Combined, these data show measurable boosting of at least two different HIV-1 targets, Env and Tat, after live SHIV-C exposures - although no viral loads were ever detected in these animals throughout the time course of observation that ranged from one to six years.

\section{Probing the virus-specific Abs: Subtractive biopanning}

Based on these quantitative changes, we addressed the question whether the virus challenge had also induced a qualitative change in the Abs responses. In other words, we sought to examine whether there were Abs with new specificities present only after - but not before - any exposure to live virus. To probe the paratopes of these new Abs, we further dissected the $A b$ repertoire in the two aviremic animals mentioned above (RRi-11 and RTr-11), using recombinant phage libraries encoding random peptides. To identify Ab responses only present after exposure to the challenge virus (in this case SHIV-1157ipEL-p [12]), we devised a novel selection strategy based upon random peptide phage display and termed "subtractive biopanning": Positive selection used plasma from a completely protected RM after all low-dose exposures (week 7). This was followed by negative counter-selection with plasma from the same animal collected two weeks after the last protein boost, corresponding to just before the first virus challenge (week 0) (Figure 1F). We hypothesized that removing phages recognized by vaccine-induced Abs would enrich for phages binding to Abs generated during the repeated mucosal virus challenges. Three rounds of alternating positive/negative selection were performed. Peptide inserts of selected recombinant phages (phagotopes) were sequenced and aligned with the Env sequence of the immunogen (HIV1084i gp160) or the challenge strain (SHIV-1157ipEL-p) to search for mimicry (mimotopes).

Depending on the positive selector used, different motifs were identified (data not shown). However, one recurring motif shared by RRi-11 and RTr-11 could be assigned to the V3 crown (linear alignment, Figure 2A), and the corresponding mimotopes were termed wk7-V3 mimotopes. To verify that the latter represented epitopes of Abs induced by the virus challenges rather than Abs induced by the gp160 1084i immunogen, we cross-tested 14 different plasma samples from each aviremic animal for 


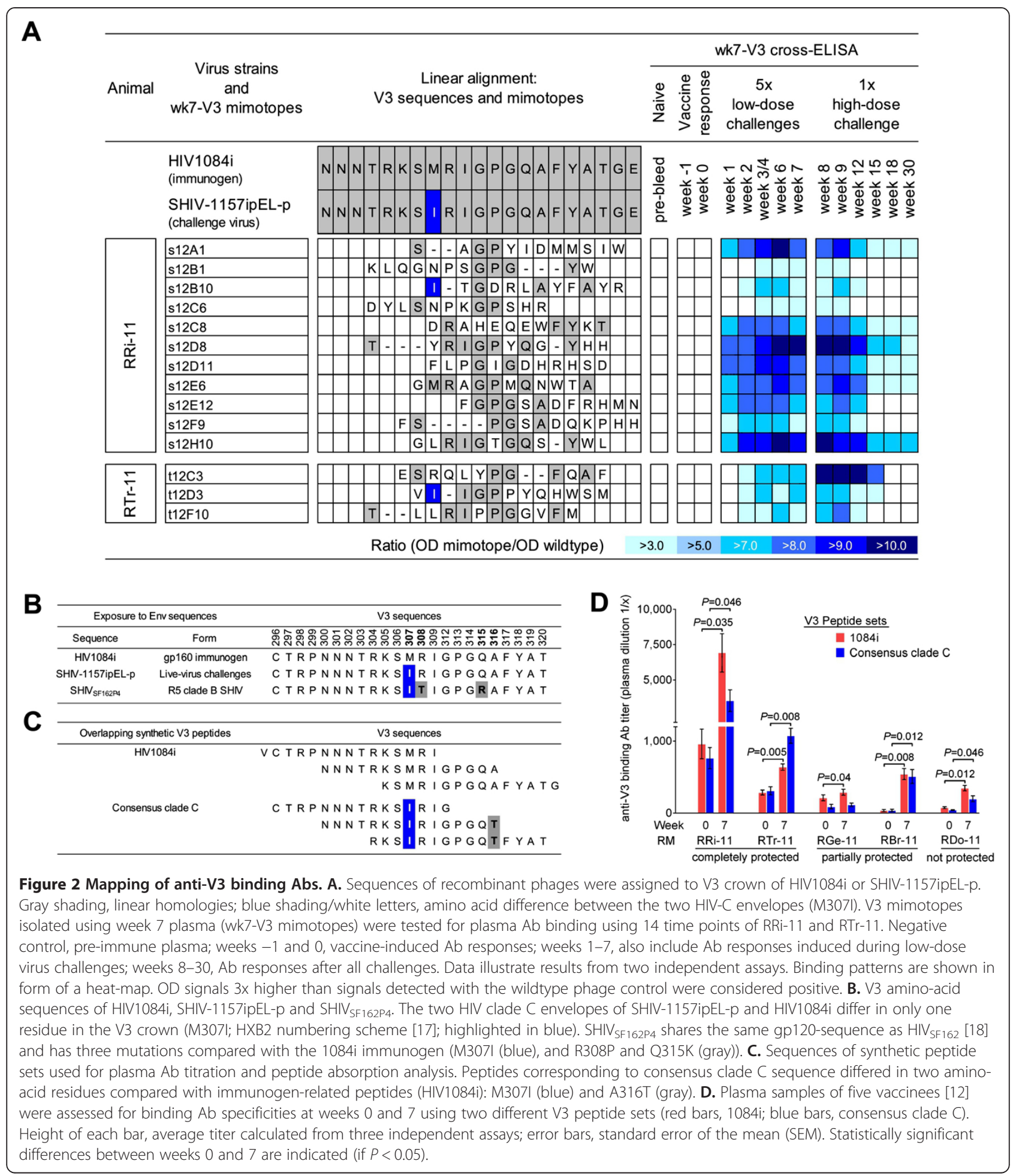

specific binding by phage ELISA. The results are presented in the form of a heat-map (Figure 2A). None of the wk7-V3 mimotopes were recognized by plasma Abs present before live-virus encounters (naïve, week -1 or week 0 samples). However, once the vaccinees were exposed to SHIV-1157ipEL-p for the first time (week 1), 8 out of 14 wk7-V3 mimotopes were specifically recognized by plasma Abs, with increasing binding reactivities at week 2 . Interestingly, these responses were strongly boosted by the single high-dose rechallenge with the same SHIV-C (Figure 2A). Overall, these data confirmed 
that our subtractive selection strategy had indeed enriched for mimotopes only recognized by Abs present after live SHIV-C exposures.

\section{Mapping of vaccine- versus virus-specific V3 Ab epitopes} The vaccinees had encountered two different HIV-C Env sequences, HIV1084i as an immunogen and SHIV1157ipEL-p as challenge virus. HIV1084i and SHIV1157ipEL-p Envs are distinct and only share 78\% amino acid (AA) homology [12]. Importantly, they differ in the V3 crown at position 307 (methionine to isoleucine switch; M307I) (Figure 2B), which affects one of three V3 core residues recently described as essential for the recognition of broadly neutralizing antibodies (bnAbs) [19]. For epitope mapping, we used two different peptide sets corresponding to the V3 crown (Figure 2C): one was identical to the HIV1084i immunogen sequence, while the other set represented a consensus clade $\mathrm{C}$ sequence and contained M307I as in the heterologous challenge virus, SHIV-1157ipEL-p. Of note, the consensus C V3 peptide set shows another AA switch (A316T) in the V3 circlet. However, this area is more variable and therefore less likely targeted by bnAbs [19].

Using the linear V3 peptides (Figure 2C), we performed binding ELISAs to confirm that the low-dose SHIV-1157ipEL-p exposures had altered Ab titers. Towards this end, we analyzed plasma samples collected at weeks 0 and 7 in the two vaccine-protected RMs, RRi-11 and RTr-11 (Figure 2D). As a comparison, we also examined three vaccinees that had been part of the same study ([12], Table 1 and time line in Figure 1A) but had detectable viral RNA: RGe-11 exhibited two transient, low-level blips $\left(<10^{4}\right.$ viral RNA copies/ml) but lymph node biopsies were virus negative. RBr-11 developed chronic systemic infection but had lower peak viremia compared with the controls and RDo- 11 was chronically infected without any signs of protection (Table 1).

Remarkably, the aviremic animals RRi-11 and RTr-11 showed significantly higher immunogen-related V3specific ELISA titers after the fifth virus challenge compared with the titers before the first live-virus encounter (Figure 2D, red bars; $P=0.035$ and $P=0.005$, respectively). As expected, the three other vaccinees that had detectable viral loads (RGe-11, RBr-11 and RDo-11) also showed a statistically significant boosting using the immunogen-related $1084 \mathrm{i}$ V3 peptides (red bars, $P=0.04, P=0.008$ and $P=0.012$, respectively). Thus, the $5 \mathrm{x}$ low-dose challenges with SHIV-1157ipEL-p boosted the vaccine-induced anti- $\mathrm{V} 3$ binding $\mathrm{Ab}$ titers in all five animals tested.

When we used the consensus C V3 peptides (blue bars), which contain the critical mutation (M307I) that is present in the challenge virus but not in the immunogen, we detected an increase of anti-V3 binding Abs in the two aviremic vaccinees, RRi-11 $(P=0.046)$ and $\mathrm{RTr}$ $11(P=0.008)$, as well as in $\mathrm{RBr}-11(P=0.012)$ and RDo$11(P=0.046)$. The anti-consensus $\mathrm{C} \mathrm{V3}$ Ab titers did not change for RM RGe-11 when samples from weeks 7 and 0 were compared (Figure 2D). Taken together, our data indicate that the five SHIV-1157ipEL-p challenges significantly boosted the pre-existing anti-V3 binding $\mathrm{Ab}$ responses. Importantly, this was also observed in two protected RMs, although no viremia was detected throughout.

\section{Boosting of vaccine-induced anti-V 3 nAbs in the absence of viremia}

To test whether the multiple SHIV-1157ipEL-p challenges had not only altered Ab binding activity but also the vaccine-induced $\mathrm{nAb}$ activity, we examined plasma samples of weeks 0 and 7 for nAb titers. Although no viremia was ever detected in animals RRi-11 and RTr11 , their $50 \%$ inhibitory concentration $\left(\mathrm{IC}_{50}\right)$ against the challenge virus increased after the $5 \times$ virus encounters (Figure 3A; white bars, $\mathrm{IC}_{50}$ of weeks 0 vs. 7). For RRi11 , the $\mathrm{IC}_{50}$ was insignificantly 1.5 -fold higher. For RTr11 , we detected a statistically significant 3.3 -fold increase $(P=0.01)$ at week 7. Clearly, live-virus exposures boosted pre-existing $\mathrm{nAb}$ responses in this aviremic vaccinee.

Next, we examined whether the increased neutralization titer noticed after live SHIV-C exposures could be linked to anti- $\mathrm{V} 3 \mathrm{nAb}$ responses. Thus, we absorbed the neutralizing activity by incubating plasma in the presence/absence of the different V3 peptide sets shown in Figure 2C. Absorption with the immunogen-related 1084i V3 peptides reduced the neutralizing activity of the week 7 plasma by $79 \%$ in RRi- $11(P=0.009)$ but not at all in RTr-11 (Figure 3A; red bars). Importantly, absorption with the consensus C V3 peptides significantly lowered the neutralizing activity after but not before live-virus exposure in both aviremic animals (blue bars; $P=0.004$ and 0.02 , respectively). Neither the partially protected nor the non-protected monkeys showed changes in $\mathrm{nAb}$ titers or $\mathrm{V} 3$ reactivity ( $\mathrm{RGe}-11, \mathrm{RBr}-11$, and RDo11, data not shown). Taken together, the peptide absorption data imply that nAbs with new target specificity had developed between weeks 0 and 7, especially in animal RTr-11 (neo-antigen reactivity; gray box and asterisk in Figure 3A).

\section{Induction of new cross-neutralizing anti-V3 antibodies in the absence of viremia}

We reasoned that $5 \times$ live-virus exposures might have induced anti-V3 nAbs that cross-neutralize a heterologous, non-clade $\mathrm{C}$ virus and tested plasma samples of weeks 0 and 7 for neutralizing activity against the clade B SHIV $_{\text {SF162P4 }}$ [21]. We used the peptide absorption described above to link neutralization to anti-V3 Abs and 

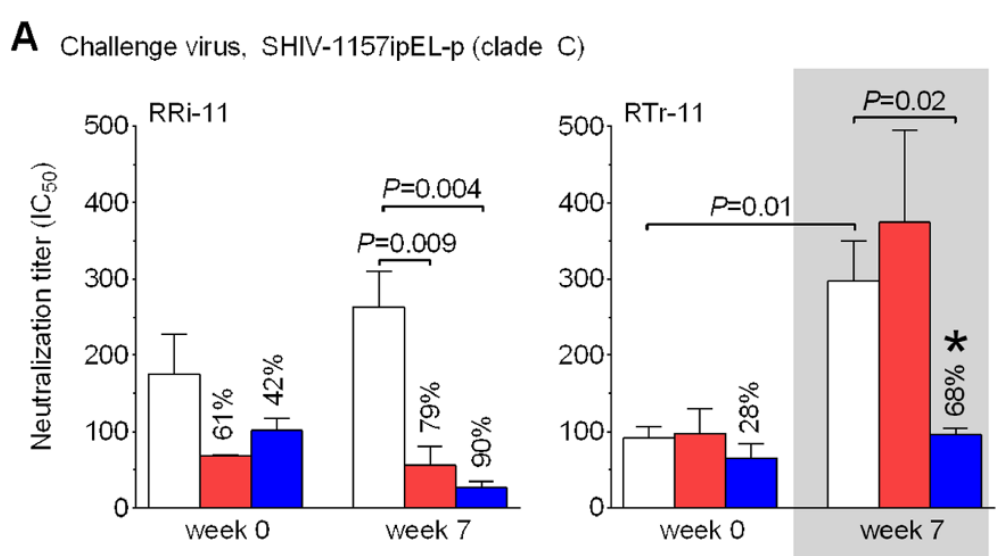

B SHIV $_{\text {SF } 162 P 4}$ (clade B)
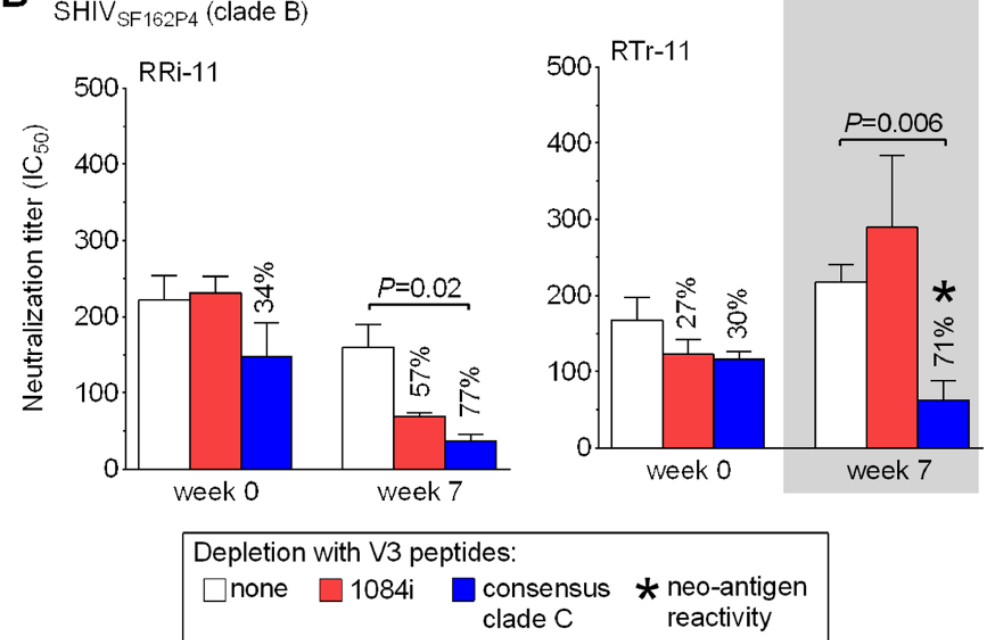

Figure 3 Induction and boosting of cross-neutralizing anti-V3 Abs in the absence of viremia. Plasma samples (weeks 0 and 7) were tested

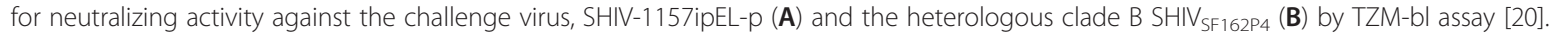
Neutralization titers are expressed as the reciprocal plasma dilution inhibiting $50 \%$ of virus infection $\left(\mathrm{IC}_{50}\right)$. Each bar represents the average titer of at least two independent assays using triplicates of each sample and error bars show the SEM. Plasma nAb titers were compared between weeks 0 (before live-virus challenges) and 7 (after $5 x$ multiple low-dose challenges). Plasma samples were incubated with either medium (plasma only, white bars) or one of the two peptide sets (red bars, 1084i V3; blue bars, consensus clade C V3) and IC $C_{50}$ values were calculated. In case of a decreased $I_{50}$ (depletion of neutralizing activity), percentages illustrate the degree of inhibition reached with each peptide set. $P$-values are shown (significance after Bonferroni correction, $P<0.025$ ). Gray box and asterisks indicate neoantigen reactivity.

noted three AA changes in the V3 crown of SHIV $\mathrm{SF}_{162 \mathrm{P} 4}$ compared with the HIV1084i immunogen (M307I, R308T and Q315R; see Figure 2B). Overall, the 5x SHIV-1157ipEL-p challenges did not increase neutralizing activity against $\mathrm{SHIV}_{\mathrm{SF162P}}$ in the two aviremic RMs (Figure 3B; white bars, $\mathrm{IC}_{50}$ of weeks 0 vs. 7). We also saw no statistically significant differences in $\mathrm{IC}_{50}$ levels at week 7 when using the immunogen-related 1084i V3 peptides (red bars). In contrast, peptide absorption showed highly significant drops in $\mathrm{IC}_{50}$ values after incubation with the consensus $\mathrm{C}$ V3 peptides (blue bars, $P=0.02$ for RRi-11 and $P=0.006$ for RTr-11). These data are consistent with an expansion of target specificity in both protected animals (neo-antigen reactivity for RTr-11; gray box and asterisk in Figure 3B) at week 7 .
No significant changes were seen for the partially protected animal RGe-11 (data not shown).

Overall, we conclude that the $5 \times$ live-virus exposures: i) boosted vaccine-induced anti-1084i V3 binding Ab titers, ii) induced anti- $\mathrm{V} 3 \mathrm{nAb}$ responses against the challenge virus SHIV-1157ipEL-p, and iii) changed the V3 loop specificity of nAbs against heterologous $\mathrm{SHIV}_{\mathrm{SF} 162 \mathrm{P} 4}$ in two animals without any signs of viremia.

\section{Discussion}

Here we describe: i) a quantitative change in the Envspecific plasma Ab titers in four out of five persistently aviremic vaccinees, ii) subtractive biopanning with recombinant phages encoding random peptides as a new tool to dissect qualitative (virus-induced) changes in the 
humoral immune responses of vaccine-protected animals, iii) an increase of vaccine-induced anti-V3 binding $\mathrm{Abs}$ and induction of novel, cross-neutralizing anti-V3 Abs due to live SHIV-C encounters in animals that had remained virus-free.

Different immunization studies performed by our group yielded a cohort of five vaccinees that resisted multiple live SHIV-C exposures completely. Here, we dissected the Env-specific Ab responses in these monkeys. More specifically, we investigated the consequences of live-virus challenges on the strength and specificity of vaccine-induced $\mathrm{Ab}$ responses in the absence of any detectable viral load. Unexpectedly, we detected higher Env-specific binding Ab titers in four out of five aviremic RMs after they had been exposed to live SHIV$\mathrm{C}$. The boosting of $\mathrm{Ab}$ responses was independent of the challenge route. Similar effects were observed after oral (for animal RAt-9 [8-10]) and intrarectal challenges (for all the other monkeys tested).

To verify that the increased anti-Env Ab titers were a direct consequence of the virus challenges, we compared the dynamics of anti-gp140 Ab responses in vaccinated RMs with or without subsequent exposures to live virus. As expected, we detected a vaccine-induced boost of $\mathrm{Ab}$ responses about two weeks after the last protein immunization in both groups of animals. Remarkably, these titers kept increasing during the repeated virus challenges although no viremia ensued. In contrast, immunization without subsequent virus challenges resulted in the expected increase in anti-gp140 Ab levels that peaked at week 2 post-immunization and continuously declined thereafter. These data confirmed a livevirus induced increase of pre-existing, vaccine-induced Ab responses.

We sought to examine the Ab repertoire in two of the protected animals further and determined whether the live-virus challenges only boosted the pre-existing, vaccine-induced responses or also induced new Abs against neo-antigens represented by the Env proteins on the challenge virus particles. Phage display [22] has been used to analyze humoral immune responses in the context of chronic infections with immunodeficiency viruses [23-27]. Here, we designed a novel subtractive biopanning strategy to probe the paratopes of virusinduced Abs in vaccine-protected animals. We hypothesized that depleting phages recognized by Abs present after immunization but before any virus exposures would select for phages recognized by live virus-induced Abs only. We performed subtractive biopannings using polyclonal plasma samples from completely protected vaccinees and analyzed the selected phagotopes for similarities to Env sequences. This approach allowed us to identify the V3 crown as an epitope specifically recognized by week 7 but not week 0 Abs and shared by the two aviremic vaccinees, although subtractive biopanning revealed other Env regions for these vaccinees individually (data not shown).

Recently, the V3 crown and its conserved structural elements that are involved in co-receptor binding were shown to be important targets for bnAbs, including mAbs 447/52-D, 2219, 3074, 33B2, 33C6 [19,28-30] and HGN194 [31]; the latter also provided complete crossclade protection against SHIV-C acquisition in vivo [32]. Together with the novel bnAbs, PG9 and PG16, targeting quaternary epitopes formed by the V2 and V3 loops in trimeric Env [33], the V3 loop is now considered again as target for vaccine development (reviewed in [28]).

By phage ELISA, we confirmed that the V3 mimotopes isolated by subtractive biopanning were only recognized after but not before the first virus challenge. Importantly, these responses were also boosted by the rechallenge with a high-dose of the same challenge virus. These data indicate that both low- and high-dose challenges can induce a similar boosting effect.

Our detailed analysis of anti-V3 responses using the actual V3 peptides revealed a significant boosting of immunogen-induced anti-HIV 1084i V3 binding Abs after the multiple low-dose challenges in five out of five vaccinees tested. Importantly, the same boosting was noticed in the two completely protected animals. This is remarkable considering that no viremia was ever detected for $>3$ years. In addition to these altered binding $\mathrm{Ab}$ titers, we also observed an increase in neutralizing activity against the challenge virus in the same aviremic RMs. Peptide absorption linked these increased $\mathrm{nAb}$ titers to anti-V3 responses. Interestingly, most of the induced cross-neutralizing anti-V3 Abs targeted the antigenically different version of the $\mathrm{V} 3$ crown presented by the challenge virus. Based on these results, we propose that the multiple live-virus exposures boosted anti-HIV-1 responses and altered their specificity in the absence of any detectable viremia.

Pre-existing antiviral immunity has been considered problematic for the recognition of antigenically diverse strains by the "primed" immune system. This idea of a compromised immune system was first discussed in the context of influenza virus antigens [34] and termed Original Antigenic Sin (OAS) [35]. Ab formation during initial influenza infections in childhood was believed to greatly influence future $\mathrm{Ab}$ formation against newer strains encountered later [34]. More specifically, vaccination with one strain of influenza virus and subsequent exposure to a heterologous strain would induce anamnestic $\mathrm{Ab}$ responses against the initial strain [35]. Later, Nara and coworkers expanded the concept of OAS to the model of deceptive imprinting and defined it as a mechanism leading to a fixed state of immunity which in turn fails to adapt to a changing, but similar pathogen 
[36,37]. Moreover, they described the induction of clonally restricted $\mathrm{B}$-cell responses due to immunodominant epitopes found on the original antigen (reviewed in [38]). With regard to HIV-1 infections, it was postulated that initial vaccine-induced $\mathrm{nAb}$ responses would target immunodominant epitopes of variable gp120 regions (especially the V3 loop), which mutate due to immune selection pressure [36]. Thus, nAb responses would be limited to the primary virus variant, which is considered potentially problematic during chronic HIV-1 infection, as well as for the formation of effective $\mathrm{nAb}$ responses against non-homologous HIV-1 strains in vaccine recipients [36-39]. Yet, we [40] and others [41-43] gave evidence that the occurrence of OAS is not absolute.

Investigating the anti- $\mathrm{V} 3$ binding $\mathrm{Ab}$ repertoire in vaccine-protected RMs, we indeed detected a statistically significant boosting of the initial vaccine-induced binding Abs after live-virus encounters with the heterologous strain, supporting the concept of OAS. However, our data do not imply a limitation in subsequent $\mathrm{Ab}$ responses against non-homologous virus strains as suggested by the model of deceptive imprinting [36,37]. Based upon the initial selection of V3 mimotopes and their specific recognition of plasma samples after but not before live SHIV-C exposures, we demonstrate a change in the $\mathrm{Ab}$ repertoire as a consequence of livevirus encounters. This neo-antigen reactivity was then confirmed indirectly by peptide absorption analysis showing the induction of nAbs against an antigenically different version of the same V3 epitope. Thus, despite the pre-existing anti-V3 Abs present after immunization, virus-challenged RMs that never developed viremia produced cross-neutralizing anti-V3 Abs targeting the epitope version presented by the challenge virus.

Of note, the boosting of virus-specific Ab responses as a consequence of live-virus exposures that failed to cause detectable viremia was not restricted to Env only. According to our recent work [16], multiple live-virus exposures also affected anti-Tat Ab responses; we showed that mimotopes displaying the N-terminus of HIV-1 Tat were only recognized by Abs of protected vaccinees, RRi11 and RTr-11, after the live-virus exposures (week 7), but not on the day of challenge (week 0 ). Subsequent quantitative ELISAs using the full-length HIV-1 Tat protein and Tat peptides confirmed an increase of anti-Tat Abs after multiple exposures to SHIV-C in three out of four aviremic vaccinees (RRi-11, RTr-11 and RAt-9). These data indicate that the virus challenges altered $\mathrm{Ab}$ responses against at least two different HIV-1 proteins, Env and Tat, in the absence of systemic infection.

Animals ROb-12, RAt-9, RRi-11 and RTr-11 were never viremic. How did the multiple low-dose virus challenges alter the vaccine-induced anti-Env and antiTat $\mathrm{Ab}$ repertoire in these animals? Theoretically, three mechanisms could be responsible: i) cryptic infection of target cells and their subsequent lysis. This may have produced sufficiently high concentrations of challenge virus proteins to induce Abs with altered specificities; ii) formation of immune complexes of virions and/or soluble protein with pre-existing, vaccine-induced Abs followed by efficient binding to and presentation by Fc-gamma receptor ( $\mathrm{Fc} \gamma \mathrm{R})$-expressing cells; iii) a combination of the two mechanisms.

In order to estimate potential mechanisms that may have been involved, we first employed an ultrasensitive HIV-1 gp120 antigen capture ELISA and used parental SHIV-1157ip gp120 [30] as reference protein. Total gp120 concentration of the virus stock solubilized in disruption buffer was only $35 \mathrm{pg}$ per challenge virus dose. This total amount of gp120 is about $10^{6}-10^{7}$ less than what has been used for standard immunizations in humans or macaques [44-48], making boosting via soluble Env a highly unlikely mechanism - especially since no adjuvant was involved in contrast to the standard vaccination/boosting protocols [44-48]. Moreover, the virus-induced boosting effect was not only detected in animals from one study [12] but in four animals derived from three different studies $([8,12]$ and unpublished). Thus, we propose that this observation is not virusstock dependent since the challenge virus strains varied among the different studies.

Cryptic infection is expected to boost antiviral cellular immunity. This was observed in some of the vaccineprotected RMs (RTr-11, RAt-9, ROb-12). In contrast, vaccinee RRi-11 had no anamnestic cellular immune responses and thus fulfilled the criteria for sterilizing immunity. For this animal, we propose that vaccineinduced nAbs not only blocked initial infection of target cells but also led to the formation of virion-antibody complexes (reviewed in [49]). Such opsonized virions may then have been taken up by follicular dendritic cells in lymph nodes, which in turn resulted in more effective presentation of Env epitopes to B cells (reviewed in $[50,51])$. Thus, we suggest that virions - although unable to cause systemic infection - might have acted as effective immunogens in the form of antigen-antibody complexes.

$\mathrm{Ab}$-covered virions also altered the anti-Tat $\mathrm{Ab}$ responses. According to Monini et al. [52], HIV-1 Tat can form a specific molecular complex with trimeric Env and hence is found on virion Env spikes. This observation would explain the boosting of pre-existing or induction of novel anti-Tat $\mathrm{Ab}$ responses.

In the current study, we examined the Env-specific $\mathrm{Ab}$ responses in five completely protected vaccinees and chose two of them to investigate the virus-induced consequences on pre-existing $\mathrm{Ab}$ responses further. At this point, it should be emphasized that well studied individual cases, as the protected monkeys described above, 
can shed light onto important basic mechanisms and potential solutions to the problems of prevention and/or cure of retroviral infections. To illustrate the power of case reports, we point to the description of a monkey with breakthrough SIV infection [53], HIV-1 superinfection in a relatively recently infected individual [54], and the "Berlin patient" [55].

In summary, we described a boosting of pre-existing, vaccine-induced $\mathrm{Ab}$ responses in immunized macaques that remained aviremic throughout all heterologous SHIV-C challenges. Furthermore, detailed epitope mapping revealed newly induced Abs specific for epitopes formed only in the challenge virus.

\section{Conclusions}

Exposures to live virus that fail to cause viremia can nevertheless result in changes in the $\mathrm{Ab}$ repertoire initially induced by vaccination. This is an important finding with implications for the analysis of immunogenicity data for clinical vaccine trials in humans. Sub-threshold virus exposure due to high risk behaviour may broaden the vaccine-induced $\mathrm{Ab}$ repertoire in the absence of systemic infection or seroconversion. Repeated live-HIV-1 exposures may complicate the interpretation of "vaccine-only" immune responses, which will be difficult to investigate. Thus, further well-controlled challenge studies in biological relevant primate models will be necessary to elucidate the underlying mechanism(s) of low-dose pathogen interactions with vaccinated hosts without overt infection.

\section{Methods}

\section{Animals}

Indian-origin RMs (Macaca mulatta) were housed at the Yerkes Regional Primate Research Center (Atlanta, GA, USA). All procedures were approved by the Animal Care and Use Committees of Emory University and the Dana-Farber Cancer Institute (DFCI). To examine Env-specific $\mathrm{Ab}$ responses induced by live-virus exposure, plasma samples were collected from RMs that had been either part of a vaccine/challenge study or an immunogenicity study. Animals of the former included ROb-12 (unpublished), RAt-9 [8-10], RQe-10 [11], RRi11, RTr-11, RGe-11, RBr-11 and RDo-11 [12]. The immune status of these vaccinees as well as immunogens and challenge viruses used are summarized in Table 1.

Group 1 animals [12] described in Figure 1 had received three protein immunizations, consisting of HIV-1 gp160, HIV-1 Tat, and SIV Gag-Pol particles (weeks33, -27 and -2). Starting two weeks after the third protein immunization (week 0), all RMs were given five weekly low-dose intrarectal (i.r.) challenges of SHIV1157ipEL-p (weeks 0-4, 8,000 50\% tissue culture infectious doses $\left(\mathrm{TCID}_{50}\right.$, measured by TZM-bl assay [20]).
At week 7, animals without evidence of viremia were rechallenged i.r. with a single high dose of the same virus $\left(1.5 \times 10^{5} \mathrm{TCID}_{50}\right)$.

Group 2 animals shown in Figure 1 (RDs-12, RFg-12, RYc-12, RGn-12, RNu-12, RMc-12, RJd-12, RGv-12; unpublished) had been treated according to a similar immunization protocol as the vaccinated and challenged animals (involving HIV-1 1084i gp160, SIV Gag-Pol particles, HIV-1 Tat) with the addition of SIV Nef overlapping synthetic peptides (OSP). All recombinant protein immunogens were given in incomplete Freund's adjuvant (IFA).

\section{Protein ELISA}

Microtiter plates (Greiner-Bio-One $\mathrm{GmbH}$, Frickenhausen, Germany) were coated with CN54-gp140 (Polymun, Scientific GmbH, Klosterneuburg, Austria); $1 \mu \mathrm{g} / \mathrm{ml}$ in $50 \mu \mathrm{l} /$ well carbonate-bicarbonate buffer (Sigma-Aldrich, St. Louis, MO, USA). After blocking for $2 \mathrm{~h}$ at room temperature with 3\% casein (Sigma-Aldrich), plasma samples were diluted 3 -fold, added to the plates (in blocking buffer) and incubated for $3 \mathrm{~h}$ at room temperature. Afterwards, Ab binding was detected using a HRP-conjugated anti-monkey IgG (1 h at room temperature, 1:2,000 in blocking buffer; Sigma-Aldrich) and o-Phenylenediamine dihydrochloride (OPD; Amresco Inc., Cochran, Solon, $\mathrm{OH}$, USA) $+\mathrm{H}_{2} \mathrm{O}_{2}$. After stopping the reaction with $1 \mathrm{~N}$ $\mathrm{H}_{2} \mathrm{SO}_{4}$, plates were read at 490/620 nm. Binding Ab titers were calculated by linear regression and defined as reciprocal plasma dilution with an absorbance $5 \times$ higher than the background absorbance, detected with the autologous pre-immune plasma.

Since the five completely protected RMs had been enrolled in four different immunization/challenge studies, the time points of the samples collected varied slightly in Figure 1E. For the "before any live-virus challenge" time point we always used week 0 , but in case of RAt-9, we analyzed week -2 because week 0 was not available. For the "after live-virus challenge" samples we analyzed the following time points: ROb-12 plasma from week 6 , RAt-9 plasma from week 30, RQe-10, RRi-11 and RTr11 plasma from weeks 6 or 7 , respectively.

\section{Subtractive biopanning}

Plasma samples of vaccinated, protected animals were used to identify specific Ab epitopes by peptide phagedisplay. Paramagnetic beads (Dynabeads M-280 tosylactivated; Invitrogen, Carlsbad CA, USA) were coated with rabbit anti-monkey IgG (as previously described [26]) and pre-incubated with polyclonal RM plasma (collected at week 7 , positive selection). After overnight incubation with the original phage-display libraries (7mer, cyclic 7mer, 12mer; New England Biolabs, Ipswich MA, USA), bound phages were eluted by $\mathrm{pH}$ shift with $0.2 \mathrm{M}$ glycine- $\mathrm{HCl} \mathrm{pH} 2.2$ supplemented with $1 \mathrm{mg} / \mathrm{ml}$ bovine 
serum albumin (BSA) and neutralized with $1 \mathrm{M}$ Tris$\mathrm{HCl} \mathrm{pH} 9.1$ (Sigma-Aldrich). Eluted phages were used in a negative selection (plasma sample from week 0 ). Remaining phages were amplified in Escherichia coli (ER2738, New England Biolabs), precipitated overnight at $4^{\circ} \mathrm{C}$ (20\% PEG-8000/2.5 M NaCl; Fisher Scientific, Fair Lawn NJ, USA) and subjected to two more rounds of selection. After the third positive selection, phages were titered, single clones were picked and then tested by phage ELISA for specific binding. Single-stranded DNA of positive clones was sequenced. Peptide sequences were grouped into motifs and assigned to the gp160 sequence of the vaccine- (HIV1084i) or challenge strain (SHIV-1157ipEL-p).

\section{Phage ELISA and cross-reactivity profile of mimotopes}

Phage ELISAs were performed as previously published [26]. As a negative control, M13KO7 helper phages (New England Biolabs) without peptide insert were included (wild type phage). Phage peptides mimicking the V3 crown were evaluated according their binding activity to polyclonal plasma Abs of different time points before and after virus challenges. Optical density (OD) signals at least $3 \times$ higher than signals detected with the negative control were considered positive and the crossreactivity profile of each mimotope was expressed as color-coded heat-map.

\section{Synthetic peptides}

Peptides corresponding to the V3 consensus clade C sequence were obtained from the NIH AIDS Reagent and Reference Reagent Program (15 amino acids (AA) long, overlapping by $11 \mathrm{AA}$ ). Peptides corresponding to HIV1084i V3 were 15 AA long, overlapping by 10 AA (CHI-Scientific, Maynard, MA, USA) (sequences see Figure 2C). A pool of three overlapping peptides was used (peptide set). As negative control, a scrambled C-terminal gp120 peptide was included (24 AA, GVTK YIPGSIPVEGLKSHKAGSYK, Molecular Biology Core Facilities, DFCI, Boston, MA).

\section{Peptide ELISA}

Microtiter plates were coated with a pool of three overlapping V3 peptides or the negative control peptide (total concentration per peptide set, $2 \mu \mathrm{g} / \mathrm{ml}$ in $100 \mu \mathrm{l} /$ well carbonate-bicarbonate buffer). After blocking for 2 $\mathrm{h}$ at room temperature with $3 \%$ casein, plasma samples were diluted 2-fold and added to the plates (in blocking buffer). Ab detection and calculation of binding Ab titers as described for the protein ELISA. Ab titers were compared at weeks 0 and 7 .

\section{Depletion of $n A b s$ using synthetic peptides}

Plasma samples were incubated in the presence/absence of V3 peptides (based on [40]) and tested against SHIV-

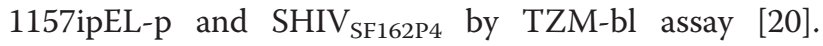
Briefly, a total of 5,000 cells/well were seeded overnight. Plasma samples were diluted 2-fold and incubated for 1 $\mathrm{h}$ at $37^{\circ} \mathrm{C}$ with a pool of three overlapping peptides (total concentration, $50 \mu \mathrm{g} / \mathrm{ml}$ ), the control peptide, or an equal volume of growth medium. Virus was incubated with the $\mathrm{Ab} /$ peptide mixture for $1 \mathrm{~h}$ at $37^{\circ} \mathrm{C}$ and afterwards transferred into the 96-well flat-bottom plate containing TZM-bl cells. After maximally $20 \mathrm{~h}$, medium was exchanged. After another $24 \mathrm{~h}$, Bright-Glo luciferase substrate (Promega, Madison, WI, USA) was used to measure luciferase activity. Neutralization titers are calculated with regard to autologous pre-immune plasma samples and expressed as the reciprocal plasma dilution inhibiting $50 \%$ of virus infection $\left(\mathrm{IC}_{50}\right)$. The ability of peptides to block nAbs is calculated as the percent reduction in neutralization titers relative to that of the corresponding plasma sample without peptide incubation.

\section{Detection of Env protein in the challenge virus preparation}

$100 \mu \mathrm{l} /$ well of the original virus preparation were used in the HIV-1 gp120 Antigen Capture Assay (Advanced Bioscience Laboratories, Rockville, MD, USA) according to the manufacturer's instructions. For more accurate estimation of the SHIV-1157ipEL-p gp120 content, we included the parental 1157ip gp120 protein as reference [30].

\section{Statistical analysis}

Statistics were calculated using a paired, two-tailed Student's t-test comparing the significance between $\mathrm{Ab}$ titers before and after five low-dose challenges. Differences with $P<0.05$ were considered statistically significant. Differences in nAb titers detected with plasma samples in the absence/presence of certain peptides were calculated using an unpaired, two-tailed Student's t-test (including Bonferroni correction: $P<0.025$ were considered statistically significant). All statistical analysis was performed using GraphPad Prism 5 for Windows, GraphPad Software.

\section{Competing interest}

The authors declare no competing financial interests.

\section{Authors' contributions}

$B C B, M H$ and RMR designed the experiments and wrote the manuscript. $B C B$ performed and analyzed the experiments. SKL and RAR performed the immunization studies. All authors read and approved the final manuscript.

\section{Acknowledgements}

We thank Drs. Quentin Sattentau, Jennifer Watkins, Hildegund Ertl as well as François Villinger for careful review of this manuscript and helpful discussions. The following reagent was obtained through the AIDS Research 
and Reference Reagent Program, Division of AIDS, NIAID, NIH: HIV Consensus Subtype C Env (15-mer) Peptides - Complete Set.

This work was supported by National Institutes of Health grants P01 Al048240 and R37 Al034266 to R.M.R., and NCRR P51 DRR00016500 to Yerkes.

\section{Author details}

${ }^{1}$ Department of Cancer Immunology and AIDS, Dana-Farber Cancer Institute, Boston, MA 02215, USA. ${ }^{2}$ VetCore Facility for Research, University of Veterinary Medicine, 1210, Vienna, Austria. ${ }^{3}$ Harvard Medical School, Boston, MA 02215, USA.

Received: 3 April 2013 Accepted: 3 June 2013

Published: 21 June 2013

\section{References}

1. Progress report 2011: Global HIV/AIDS response (UNAIDS). [http://www.who. int/hiv/pub/progress_report2011/en/index.html]

2. McElrath MJ, Haynes BF: Induction of immunity to human immunodeficiency virus type-1 by vaccination. Immunity 2010, 33:542-554

3. Rerks-Ngarm S, Pitisuttithum P, Nitayaphan S, Kaewkungwal J, Chiu J, Paris R, Premsri N, Namwat C, de Souza M, Adams E, et al: Vaccination with ALVAC and AIDSVAX to prevent HIV-1 infection in Thailand. N Engl J Med 2009, 361:2209-2220.

4. Haynes BF, Gilbert PB, McElrath MJ, Zolla-Pazner S, Tomaras GD, Alam SM, Evans DT, Montefiori DC, Karnasuta C, Sutthent R, et al: Immune-correlates analysis of an HIV-1 vaccine efficacy trial. N Engl J Med 2012, 366:1275-1286.

5. McMichael AJ, Haynes BF: Lessons learned from HIV-1 vaccine trials: new priorities and directions. Nat Immunol 2012, 13:423-427.

6. Lakhashe SK, Silvestri G, Ruprecht RM: No acquisition: A new ambition for HIV vaccine development? Curr Opin Virol 2011, 1:246-253.

7. Vlasak J, Ruprecht RM: AIDS vaccine development and challenge viruses: getting real. AIDS 2006, 20:2135-2140.

8. Rasmussen RA, Ong H, Song R, Chenine AL, Ayash-Rashkovsky M, Hu SL, Polacino P, Else JG, Novembre FJ, Ruprecht RM: Efficacy of a multigenic protein vaccine containing multimeric HIV gp160 against heterologous SHIV clade C challenges. AIDS 2007, 21:1841-1848.

9. Rasmussen RA, Lakhashe SK, Ruprecht RM: Bimodal AIDS vaccine approach: induction of cellular as well as humoral immunity can protect from systemic infection. Vaccine 2010, 28(Suppl 2):B25-B31.

10. Rasmussen RA, Siddappa NB, Lakhashe SK, Watkins J, Villinger F, Ibegbu C, Florese RH, Robert-Guroff M, Montefiori DC, Forthal DN, et al: High-level, lasting antiviral immunity induced by a bimodal AIDS vaccine and boosted by live-virus exposure: prevention of viremia. AIDS 2011, 26:149-155.

11. Lakhashe SK, Velu V, Sciaranghella G, Siddappa NB, Dipasquale JM, Hemashettar G, Yoon JK, Rasmussen RA, Yang F, Lee SJ, et al: Prime-boost vaccination with heterologous live vectors encoding SIV gag and multimeric HIV-1 gp160 protein: efficacy against repeated mucosal R5 clade C SHIV challenges. Vaccine 2011, 29:5611-5622.

12. Lakhashe SK, Wang W, Siddappa NB, Hemashettar G, Polacino P, Hu SL, Villinger F, Else JG, Novembre FJ, Yoon JK, et al: Vaccination against Heterologous R5 Clade C SHIV: Prevention of Infection and Correlates of Protection. PLoS One 2011, 6:e22010.

13. Siddappa NB, Hemashettar G, Wong YL, Lakhashe S, Rasmussen RA, Watkins JD, Novembre FJ, Villinger F, Else JG, Montefiori DC, Ruprecht RM: Development of a tier 1 R5 clade $C$ simian-human immunodeficiency virus as a tool to test neutralizing antibody-based immunoprophylaxis. J Med Primatol 2011, 40:120-128.

14. Siddappa NB, Song R, Kramer VG, Chenine AL, Velu V, Ong H, Rasmussen RA, Grisson RD, Wood C, Zhang H, et al: Neutralization-sensitive R5-tropic simian-human immunodeficiency virus SHIV-2873Nip, which carries env isolated from an infant with a recent HIV clade C infection. J Virol 2009, 83:1422-1432

15. Song RJ, Chenine AL, Rasmussen RA, Ruprecht CR, Mirshahidi S, Grisson RD, Xu W, Whitney JB, Goins LM, Ong H, et al: Molecularly cloned SHIV1157ipd3N4: a highly replication- competent, mucosally transmissible R5 simian-human immunodeficiency virus encoding HIV clade C Env. J Virol 2006, 80:8729-8738.

16. Bachler BC, Humbert M, Palikuqi B, Siddappa NB, Lakhashe SK, Rasmussen RA, Ruprecht RM: Novel biopanning strategy to identify epitopes associated with vaccine protection. J Viro/ 2013, 87:4403-4416.
17. Ratner L, Fisher A, Jagodzinski LL, Mitsuya H, Liou RS, Gallo RC, Wong-Staal $\mathrm{F}$ : Complete nucleotide sequences of functional clones of the AIDS virus. AIDS Res Hum Retroviruses 1987, 3:57-69.

18. Polacino P, Larsen K, Galmin L, Suschak J, Kraft Z, Stamatatos L, Anderson D, Barnett SW, Pal R, Bost K, et al: Differential pathogenicity of SHIV infection in pig-tailed and rhesus macaques. J Med Primato/ 2008, 37(Suppl 2):13-23.

19. Jiang X, Burke V, Totrov M, Williams C, Cardozo T, Gorny MK, Zolla-Pazner S, Kong XP: Conserved structural elements in the V3 crown of HIV-1 gp120. Nat Struct Mol Biol 2010, 17:955-961.

20. Montefiori DC: Evaluating neutralizing antibodies against HIV, SIV, and SHIV in luciferase reporter gene assays. Curr Protoc Immunol 2005, 64:12.11.1-12.11.17. Chapter 12:Unit 1211.

21. Tan RC, Harouse JM, Gettie A, Cheng-Mayer C: In vivo adaptation of SHIV (SF162): chimeric virus expressing a NSI, CCR5-specific envelope protein. J Med Primatol 1999, 28:164-168.

22. Smith GP, Petrenko VA: Phage Display. Chem Rev 1997, 97:391-410.

23. Scala G, Chen X, Liu W, Telles JN, Cohen OJ, Vaccarezza M, Igarashi T, Fauci AS: Selection of HIV-specific immunogenic epitopes by screening random peptide libraries with HIV-1-positive sera. J Immunol 1999, 162:6155-6161.

24. Enshell-Seijffers D, Smelyanski L, Vardinon N, Yust I, Gershoni JM: Dissection of the humoral immune response toward an immunodominant epitope of HIV: a model for the analysis of antibody diversity in HIV + individuals. FASEB J 2001, 15:2112-2120.

25. Humbert M, Antoni S, Brill B, Landersz M, Rodes B, Soriano V, Wintergerst U, Knechten H, Staszewski S, von Laer D, et al: Mimotopes selected with antibodies from HIV-1-neutralizing long-term non-progressor plasma. Eur J Immunol 2007, 37:501-515.

26. Humbert M, Rasmussen RA, Ong H, Kaiser FM, Hu SL, Ruprecht RM: Inducing cross-clade neutralizing antibodies against HIV-1 by immunofocusing. PLoS One 2008, 3:e3937.

27. Dieltjens T, Willems B, Coppens S, Van Nieuwenhove L, Humbert M, Dietrich U, Heyndrickx L, Vanham G, Janssens W: Unravelling the antigenic landscape of the HIV-1 subtype A envelope of an individual with broad cross-neutralizing antibodies using phage display peptide libraries. J Virol Methods 2010, 169:95-102

28. Zolla-Pazner S, Cardozo T: Structure-function relationships of HIV-1 envelope sequence-variable regions refocus vaccine design. Nat Rev Immunol 2010, 10:527-535.

29. Hioe CE, Wrin T, Seaman MS, Yu X, Wood B, Self S, Williams C, Gorny MK, Zolla-Pazner S: Anti-V3 monoclonal antibodies display broad neutralizing activities against multiple HIV-1 subtypes. PLoS One 2010, 5:e10254.

30. Sholukh AM, Mukhtar MM, Humbert M, Essono SS, Watkins JD, Vyas HK, Shanmuganathan V, Hemashettar G, Kahn M, Hu SL, et al: Isolation of monoclonal antibodies with predetermined conformational epitope specificity. PLoS One 2012, 7:e38943.

31. Corti D, Langedijk JP, Hinz A, Seaman MS, Vanzetta F, Fernandez-Rodriguez BM, Silacci C, Pinna D, Jarrossay D, Balla-Jhagjhoorsingh S, et al: Analysis of memory $B$ cell responses and isolation of novel monoclonal antibodies with neutralizing breadth from HIV-1-infected individuals. PLoS One 2010, 5:e8805.

32. Watkins JD, Siddappa NB, Lakhashe SK, Humbert M, Sholukh A, Hemashettar G, Wong YL, Yoon JK, Wang W, Novembre FJ, et al: An anti-HIV-1 V3 loop antibody fully protects cross-clade and elicits T-cell immunity in macaques mucosally challenged with an R5 clade C SHIV. PLoS One 2011, 6:e18207.

33. Walker LM, Phogat SK, Chan-Hui PY, Wagner D, Phung P, Goss JL, Wrin T, Simek MD, Fling S, Mitcham JL, et al: Broad and potent neutralizing antibodies from an African donor reveal a new HIV-1 vaccine target. Science 2009, 326:285-289.

34. Davenport FM, Hennessy AV, Francis T Jr: Epidemiologic and immunologic significance of age distribution of antibody to antigenic variants of influenza virus. J Exp Med 1953, 98:641-656.

35. Fazekas De St G, Webster RG: Disquisitions of Original Antigenic Sin. I. Evidence in man. J Exp Med 1966, 124:331-345.

36. Kohler $\mathrm{H}$, Muller S, Nara PL: Deceptive imprinting in the immune response against HIV-1. Immunol Today 1994, 15:475-478.

37. Nara PL, Garrity R: Deceptive imprinting: a cosmopolitan strategy for complicating vaccination. Vaccine 1998, 16:1780-1787.

38. Muller S: Avoiding deceptive imprinting of the immune response to HIV1 infection in vaccine development. Int Rev Immunol 2004, 23:423-436. 
39. Tobin GJ, Trujillo JD, Bushnell RV, Lin G, Chaudhuri AR, Long J, Barrera J, Pena L, Grubman MJ, Nara PL: Deceptive imprinting and immune refocusing in vaccine design. Vaccine 2008, 26:6189-6199.

40. Rasmussen RA, Montefiori DC, Robinson HL, McClure HM, Ruprecht RM: Heterologous neutralizing antibody induction in a simian-human immunodeficiency virus primate model: lack of original antigenic sin. $J$ Infect Dis 2001, 184:1603-1607.

41. Klinman DM, Higgins KW, Conover J: Sequential immunizations with rgp120s from independent isolates of human immunodeficiency virus type 1 induce the preferential expansion of broadly crossreactive B cells. J Exp Med 1991, 173:881-887.

42. Wrammert J, Smith K, Miller J, Langley WA, Kokko K, Larsen C, Zheng NY, Mays I, Garman L, Helms C, et al: Rapid cloning of high-affinity human monoclonal antibodies against influenza virus. Nature 2008, 453:667-671.

43. Zehn D, Turner MJ, Lefrancois L, Bevan MJ: Lack of original antigenic sin in recall CD8(+) T cell responses. J Immunol 2010, 184:6320-6326.

44. Kumar A, Lifson JD, Silverstein PS, Jia F, Sheffer D, Li Z, Narayan O: Evaluation of immune responses induced by HIV-1 gp120 in rhesus macaques: effect of vaccination on challenge with pathogenic strains of homologous and heterologous simian human immunodeficiency viruses. Virology 2000, 274:149-164.

45. Francis DP, Heyward WL, Popovic V, Orozco-Cronin P, Orelind K, Gee C, Hirsch A, Ippolito T, Luck A, Longhi M, et al: Candidate HIV/AIDS vaccines: lessons learned from the World's first phase III efficacy trials. AIDS 2003, 17:147-156

46. Morner A, Jansson M, Bunnik EM, Scholler J, Vaughan R, Wang Y, Montefiori DC, Otting N, Bontrop R, Bergmeier LA, et al: Immunization with recombinant HLA classes I and II, HIV-1 gp140, and SIV p27 elicits protection against heterologous SHIV infection in rhesus macaques. J Virol 2011, 85:6442-6452.

47. Stott EJ, Almond N, Kent K, Walker B, Hull R, Rose J, Silvera P, Sangster R, Corcoran $T$, Lines J, et al: Evaluation of a candidate human immunodeficiency virus type 1 (HIV-1) vaccine in macaques: effect of vaccination with HIV-1 gp120 on subsequent challenge with heterologous simian immunodeficiency virus-HIV-1 chimeric virus. J Gen Virol 1998, 79(Pt 3):423-432.

48. Mascola JR, Snyder SW, Weislow OS, Belay SM, Belshe RB, Schwartz DH, Clements ML, Dolin R, Graham BS, Gorse GJ, et al: Immunization with envelope subunit vaccine products elicits neutralizing antibodies against laboratory-adapted but not primary isolates of human immunodeficiency virus type 1. The National Institute of Allergy and Infectious Diseases AIDS Vaccine Evaluation Group. J Infect Dis 1996, 173:340-348.

49. Zinkernagel RM: Immunological memory not equal protective immunity. Cell Mol Life Sci 2012, 69:1635-1640.

50. Cyster JG: B cell follicles and antigen encounters of the third kind. Nat Immunol 2010, 11:989-996.

51. Batista FD, Harwood NE: The who, how and where of antigen presentation to B cells. Nat Rev Immunol 2009, 9:15-27.

52. Monini P, Cafaro A, Srivastava IK, Moretti S, Sharma VA, Andreini C, Chiozzini C, Ferrantelli F, Cossut MR, Tripiciano A, et al: HIV-1 tat promotes integrinmediated HIV transmission to dendritic cells by binding Env spikes and competes neutralization by anti-HIV antibodies. PLoS One 2012, 7:e48781.

53. Barouch DH, Kunstman J, Kuroda MJ, Schmitz JE, Santra S, Peyerl FW, Krivulka GR, Beaudry K, Lifton MA, Gorgone DA, et al: Eventual AIDS vaccine failure in a rhesus monkey by viral escape from cytotoxic $T$ lymphocytes. Nature 2002, 415:335-339.

54. Altfeld M, Allen TM, Yu XG, Johnston MN, Agrawal D, Korber BT, Montefiori DC, O'Connor DH, Davis BT, Lee PK, et al: HIV-1 superinfection despite broad CD8+ T-cell responses containing replication of the primary virus. Nature 2002, 420:434-439.

55. Hutter G, Nowak D, Mossner M, Ganepola S, Mussig A, Allers K, Schneider T, Hofmann J, Kucherer C, Blau O, et al: Long-term control of HIV by CCR5 Delta32/Delta32 stem-cell transplantation. N Engl J Med 2009, 360:692-698.

\section{doi:10.1186/1742-4690-10-63}

Cite this article as: Bachler et al:: Live-virus exposure of vaccineprotected macaques alters the anti-HIV-1 antibody repertoire in the absence of viremia. Retrovirology 2013 10:63.

\section{Submit your next manuscript to BioMed Central and take full advantage of:}

- Convenient online submission

- Thorough peer review

- No space constraints or color figure charges

- Immediate publication on acceptance

- Inclusion in PubMed, CAS, Scopus and Google Scholar

- Research which is freely available for redistribution 